\title{
Comparing the effects of epidural methylprednisolone acetate injected in patients with pain due to lumbar spinal stenosis or herniated disks: a prospective study
}

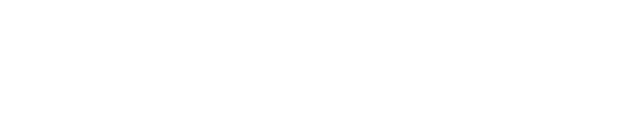

Jafar Mobaleghi'

Faramarz Allahdini ${ }^{2}$

Karim Nasseri ${ }^{3}$

Behzad Ahsan ${ }^{3}$

Shoaleh Shami ${ }^{4}$

Mansour Faizi ${ }^{5}$

Fardin Gharibi ${ }^{5}$

'Department of Surgery, ${ }^{2}$ Department of Neurosurgery, ${ }^{3}$ Department of Anesthesia, ${ }^{4}$ Faculty of Nursing,

${ }^{5}$ Faculty of Medicine, Kurdistan University of Medical Sciences, Sanandaj, Kurdistan, Iran
Correspondence: Karim Nasseri Department of Anesthesia, Kurdistan University of Medical Sciences, Beasat Hospital, Sanandaj, Kurdistan, Iran Tel +988716660733

Fax+9887I6660733

Email nasseri_k@muk.ac.ir
Objective: Satisfactory results have been seen with epidural steroid injections (ESI) in patients with herniated disks (HD), but the role in lumbar spinal stenosis (LSS) has been less investigated. We compared long-term effects of ESI in HD and LSS patients.

Methods: In a prospective, single-blind uncontrolled study, 60 patients with radicular pain due to HD $(n=32)$ or LSS $(n=28)$ were enrolled over a 9-month period. Methylprednisolone acetate $80 \mathrm{mg}$ plus $0.5 \%$ bupivacaine $10 \mathrm{mg}$ were diluted in normal saline up to a total volume of $10 \mathrm{~mL}$, and injected into the epidural space. The amount of pain based on numeric pain score, level of activity, and subjective improvement were reported by patients after 2 and 6 months by telephone. Demographic data were analyzed with the chi-square test. The differences in numeric pain scale scores between the two groups at different times were analyzed with the $t$-test.

Results: There were no differences between HD and LSS patients regarding age, sex, and average duration of pain prior to ESI. The degree of pain was significantly higher in LSS patients in comparison with HD patients in the pre-injection period. The amount of pain was significantly reduced in both groups 2 months after injection. This pain reduction period lasted for 6 months in the HD group, but to a lesser extent in LSS patients $(P<0.05)$.

Discussion: Epidural methylprednisolone injection has less analgesic effect in LSS, with less permanent effect in comparison with HD.

Keywords: methylprednisolone acetate, lumbar spinal stenosis, herniated disk

\section{Introduction}

Low back pain (LBP) is one of the most commonly presented complaints in humans, and is reported by all age groups. ${ }^{1}$ The causes of LBP may vary according to age. Mechanical LBP and herniated disk (HD) syndromes are the most common diagnoses in younger patients while lumbar spinal stenosis (LSS), which is a degenerative condition, primarily prevails in the older patient population. ${ }^{2}$

Treatment of LBP varies from conservative to operative modalities with different results. ${ }^{1}$ Epidural corticosteroid injections (ESI) have been used frequently for patients with HD with satisfying results, ${ }^{3}$ but the role of ESI in LSS is less often investigated. ${ }^{1,3}$

The aims of this study were to compare the response to ESI in patients with LSS and HD. 


\section{Material and methods}

In a prospective, single-blind uncontrolled study, patients with radicular pain due to HD were enrolled over a period of 9 months from November 2009 to July 2010.

Inclusion criteria included symptomatic HD or LSS, diagnosed with magnetic resonance imaging scan, LBP for more than 6 weeks, and age 18-60 years. Exclusion criteria included spondylolisthesis, cauda equina syndrome, progressive neurologic deficit, or other organic pathology requiring surgical intervention.

Before the procedure, the patients completed a consent form and were asked to rate their current pain on a 10 numeric pain scale (NPS) on the day of treatment. Then ESI was performed by a trained anesthetist with a midline approach and a 16-gauge Tuohy disposable needle inserted in the sitting position, and sterile operating room conditions. Entrance into the epidural space was determined using the loss of resistance method. Methylprednisolone acetate $80 \mathrm{mg}$ plus $0.5 \%$ bupivacaine $10 \mathrm{mg}$ was diluted in normal saline to a total volume of $10 \mathrm{~mL}$, and injected into the epidural space, in the L3-L4 or L4-L5 space. The amount of pain, level of physical impairment index (using the Waddell et al method), ${ }^{4}$ and subjective improvement were reported after 2 and 6 months by telephone.

\section{Statistical analysis}

The data were analyzed using SPSS for Windows, Version 12. Differences between LSS and HD patients in terms of demographics were analyzed with the chi-square test. The principal dependent variable was the difference in NPS score (at baseline, 2 months, and 6 months), and was analyzed with the $t$-test.

\section{Results}

Sixty patients (32 HD and 28 LSS) underwent ESI and were observed for 6 months. There were no differences between patients of the two groups regarding age, sex, mean duration of pain prior to ESI, body mass index (BMI), and preinjection physical impairment index (Table 1). The degree of pain was significantly higher in LSS in comparison with HD patients in the pre-injection period (Table 2). Pain was reduced in both groups 2 months after injection. The degree of pain at 2 and 6 months was significantly lower in HD compared to LSS patients ( $P=0.007$ and $P=0.04$, respectively) (Table 2). There was no correlation between age, sex, duration of pain, BMI, and pain intensity according to NPS with efficacy of ESI. Three LSS patients and one HD patient underwent surgery. There was one case of chest pain followed by hypotension about 10 minutes after ESI, which was treated with phenylephrine $100 \mu \mathrm{g}$ and meperidine $30 \mathrm{mg}$.
Table I Differences in demographic data, symptoms, and physical findings between LSS and HD patients

\begin{tabular}{llll}
\hline Variables & $\begin{array}{l}\text { LSS } \\
(\mathbf{n}=\mathbf{2 8})\end{array}$ & $\begin{array}{l}\text { HD } \\
(\mathbf{n}=\mathbf{3 2})\end{array}$ & P value \\
\hline Age (year) (mean \pm SD) & $46.7 \pm 12.1$ & $42.6 \pm 10.9$ & 0.17 \\
Sex (male/female) & $12 / 16$ & $17 / 15$ & $>0.05$ \\
Pain duration (months) (mean \pm SD) & $25.3 \pm 25.2$ & $21.8 \pm 19.6$ & 0.5 \\
Body mass index (mean \pm SD) & $25.7 \pm 2.8$ & $25.5 \pm 3.5$ & 0.5 \\
Pre-injection physical impairment index (number percent) \\
Active & $4(14.3 \%)$ & $5(15.6 \%)$ \\
Reduced productivity & $14(50 \%)$ & $18(56.3 \%)$ & 0.6 \\
Not active & $10(35.7 \%)$ & $9(28.1 \%)$ & \\
\hline
\end{tabular}

Abbreviations: LSS, lumbar spinal stenosis; HD, herniated disk.

\section{Discussion}

The pathophysiology of LBP is multifactorial, and the proinflammatory chemicals such as phospholipase A2, 5 interleukin-6, interleukin-8, prostaglandin E2, leukotriene B4, and thromboxane B2 may play major roles. ${ }^{7,8}$

The methods of treatment also vary from noninvasive modalities to surgical treatment. One of the safest and relatively noninvasive methods of treatment is ESI. More effective results have been shown with methylprednisolone, and in longstanding back pain. ${ }^{1}$ Failed back surgery syndrome, HD, and symptomatic LSS are among specific diagnoses which might be treated by ESI., ${ }^{9}$ Corticosteroids supposedly inhibit the neuropeptide synthesis and transmission in unmyelinated $\mathrm{C}$ fibers, suppress inflammation, stabilize the membrane, and have some anesthetic action which reduces sensory symptoms. ${ }^{10-12}$

Generally, the overall success rate of ESI ranges from $63 \%$ to $80 \% .^{11,12}$ In our study, the average success rate was $73.7 \%$ and $26.3 \%$ in HD and LSS patients, respectively. Patient selection, technique of injection, dosage of corticosteroid, follow-up, the route of administration, injected drugs, and utilization of fluoroscopy are among factors that may influence results. ${ }^{13}$

Runu et al reported poor responses to ESI in obese, multilevel, and large disk prolapse patients. ${ }^{1}$ There was no correlation between ESI and BMI, sex, and duration of pain in our study.

Table 2 Degree of pain in patients of two groups during different times

\begin{tabular}{llll}
\hline Variables & $\begin{array}{l}\text { LSS }(\mathbf{n}=\mathbf{2 8}) \\
(\text { mean } \pm \text { SD) }\end{array}$ & $\begin{array}{l}\text { HD }(\mathbf{n}=\mathbf{3 2}) \\
(\text { mean } \pm \text { SD) }\end{array}$ & P value \\
\hline Pre-injection pain & $7.0 \pm 1.3$ & $6.3 \pm 1.1$ & 0.02 \\
Pain 2 months after injection & $4.8 \pm 2.3$ & $3.1 \pm 2.0$ & 0.007 \\
Pain 6 months after injection & $4.4 \pm 2.8$ & $2.9 \pm 2.5$ & 0.04 \\
\hline
\end{tabular}

Abbreviations: LSS, lumbar spinal stenosis; HD, herniated disk. 
We decided to evaluate the efficacy of ESI after 2 months because therapeutic decay phenomenon has been observed with ESI, and early response could be due to the local effect of corticosteroids which have been shown to last at least 3 weeks at the therapeutic site. White et al prospectively studied 300 patients and reported good results in the early period..$^{14}$ The effect of ESI was found to decrease with time. They reported $82 \%$ pain relief at day $1,50 \%$ at 2 weeks, and $16 \%$ at 2 months. Buttermann reported the effectiveness of ESI for up to 3 years by nearly $50 \%$ of patients with HD who had not had improvement with more than 6 weeks of noninvasive care. ${ }^{3}$ Another study showed significant pain relief in $86 \%$ of patients with HD who underwent injection of local anesthetic mixed with nonparticulate betamethasone. ${ }^{15}$ In our 6-month follow-up of patients, the results were poorer than the aforementioned three studies in both HD and LSS patients. However, pain relief lasted longer in HD patients than in LSS patients.

Schoenfeld and Weiner suggested a 3-4-week course of conservative management before epidural corticosteroid injection. ${ }^{16}$ We extended this time to 6 weeks, and only included the patients with poor response to conservative methods for 6 weeks. Our results showed that more patients with HD responded to ESI in comparison to LSS. Theoretically, LSS is the result of destruction of the posterior joints which cause synovial reaction, cartilage destruction, osteophyte formation, and intervertebral disk disruption. These changes can lead to loss of disk height and facet instability. Subsequently, the neural foramina and spinal canal are narrowed, impinging upon the structures within them, including the spinal cord, nerve roots, and cauda equina. ${ }^{17}$

For the analgesic effectiveness of epidural corticosteroid, the volume and route of injection would have a considerable influence on the distribution of solutions and clinical benefits but it is restricted to $10 \mathrm{~mL} \cdot{ }^{18} \mathrm{Kim}$ et al documented epidurographically that a $10-\mathrm{mL}$ solution bolus reaches far enough to mid and lower lumbar area, and extra volumes or repeated injections could not significantly change the blocked level. ${ }^{19}$ We used a $10-\mathrm{mL}$ corticosteroid bolus for injection of the interlaminar epidural space. However, some authors suggest that transforaminal epidural corticosteroid injection provides a lower volume of concentrated medication to a selected nerve root compared to interlaminar epidural corticosteroid. ${ }^{20}$

\section{Limitations}

The strength of our results is limited by a lack of placebo group. Thus, we are not able to attribute pain relief to drug effects entirely. In addition, we used only 10 NPS for assessment of pain which may limit the strength of our results.

\section{Conclusion}

Epidural methylprednisolone injection has less analgesic effect in patients with LSS compared to HD, with less permanent effect.

\section{Acknowledgments}

This study was derived from the medical thesis of Dr Mansour Faizi. We are grateful to Mrs Azar Moqbel and Mrs Fatemeh Salehi Saheb for their help in data collection. The results from this study have been presented at the World Anesthesia Congress, April 2011, Rome, Italy.

\section{Disclosure}

The authors report no conflicts of interest in this work.

\section{References}

1. Runu R, Sinha NK, Pai R, Shankar PR, Vijayabhaskar P. Our experience with epidural steroid injections in management of low backpain and sciatica. Kathmandu Univ Med J. 2005;3:349-354.

2. Rivest C, Katz JN, Ferrante FM, Jamison RN. Effects of epidural steroid injection on pain due to lumbar spinal stenosis or herniated disks: a prospective study. Arthritis Care Res. 1998;11:291-297.

3. Buttermann GR. Treatment of lumbar disc herniation: epidural steroid injection compared with discectomy. A prospective, randomized study. J Bone Joint Surg Am. 2004;86:670-679.

4. Waddell G, Somerville D, Henderson I, Newton M. Objective clinical evaluation of physical impairment in chronic low back pain. Spine (Phila Pa 1976). 1992;17:617-628.

5. Biyani A, Andersson GB. Low back pain: pathophysiology and management. J Am Acad Orthop Surg. 2004;12:106-115.

6. Piperno M, Hellio le Graverand MP, Reboul P, et al. Phospholipase A2 activity in herniated lumbar discs. Clinical correlations and inhibition by piroxicam. Spine (Phila Pa 1976). 1997;22:2061-2065.

7. Burke JG, Watson RW, McCormack D, Dowling FE, Walsh MG, Fitzpatrick JM. Intervertebral discs which cause low back pain secrete high levels of proinflammatory mediators. J Bone Joint Surg Br. 2002;84:196-201.

8. Park $\mathrm{CH}$, Lee $\mathrm{SH}$. Investigation of high-sensitivity $\mathrm{C}$-reactive protein and erythrocyte sedimentation rate in low back pain patients. Korean J Pain. 2010;23:147-150.

9. Atlas SJ, Delitto A. Spinal stenosis: surgical versus nonsurgical treatment. Clin Orthop Relat Res. 2006;443:198-207.

10. Kalichman L, Hunter DJ. Diagnosis and conservative management of degenerative lumbar spondylolisthesis. Eur Spine J. 2007;17: 327-335.

11. Winnie AP, Hartman JT, Meyers HL Jr, Ramamurthy S, Barangan V. Pain clinic II: intradural and extradural corticosteroids in sciatica. Anesth Analg. 1972;51:990-1003.

12. Manchikanti L, Pampati V, Cash KA. Protocol for evaluation of the comparative effectiveness of percutaneous adhesiolysis and caudal epidural steroid injections in low back and/or lower extremity pain without post surgery syndrome or spinal stenosis. Pain Physician. 2010;13:E91-E110.

13. William KD, Park AL. Low back pain and disorders of intervertebral discs. In: Canale ST, editor. Campbell's operative orthopedics. Vol-II. 10th ed. Philadelphia, PA. Mosby; 2003:1961-2003. 
14. White AH, Derby R, Wynne G. Epidural injections for the diagnosis and treatment of low-back pain. Spine (Phila Pa 1976). 1980;5:78-86.

15. Manchikanti L, Singh V, Falco FJ, Cash KA, Pampati V. Evaluation of the effectiveness of lumbar interlaminar epidural injections in managing chronic pain of lumbar disc herniation or radiculitis: a randomized, double-blind, controlled trial. Pain Physician. 2010;13:343-355.

16. Schoenfeld AJ, Weiner BK. Treatment of lumbar disc herniation: Evidence-based practice. Int J Gen Med. 2010;21:209-214.

17. Yi X, McPherson B. Application of X STOP device in the treatment of lumbar spinal stenosis. Pain Physician. 2010;13:327-336.
18. Weinstein SM, Herring SA, Derby R. Contemporary concepts in spine care. Epidural steroid injections. Spine (Phila Pa 1976). 1995;20:1842-1846.

19. Kim KM, Kim HS, Choi KH, Ahn WS. Cephalic spreading levels after volumetric caudal epidural injections in chronic low back pain. $J$ Korean Med Sci. 2001;16:193-197.

20. Lee JW, Kim SH, Lee IS, et al. Therapeutic effect and outcome predictors of sciatica treated using transforaminal epidural steroid injection. Am J Roentgenol. 2006;187:1427-1431.

\section{Publish your work in this journal}

The International Journal of General Medicine is an international, peer-reviewed open-access journal that focuses on general and internal medicine, pathogenesis, epidemiology, diagnosis, monitoring and treatment protocols. The journal is characterized by the rapid reporting of reviews, original research and clinical studies across all disease areas.
A key focus is the elucidation of disease processes and management protocols resulting in improved outcomes for the patient. The manuscript management system is completely online and includes a very quick and fair peer-review system. Visit http://www.dovepress.com/ testimonials.php to read real quotes from published authors.

Submit your manuscript here: http://www.dovepress.com/international-journal-of-general-medicine-journal 